Al-Khwarizmi: Jurnal Pendidikan Matematika dan Ilmu Pengetahuan Alam Oktober-2019, Vol.7, No.2, hal.79-86

$\operatorname{ISSN}(P):$ 2337-7666; ISSN(E):2541-6499

https://ejournal.iainpalopo.ac.id/index.php/al-khwarizmi

DOI: http://dx.doi.org/10.24256/jpmipa.v7i2.707

\title{
Pengaruh Model Pembelajaran Kooperatif Tipe Index Card Match terhadap Hasil Belajar Matematika Siswa
}

\author{
Esty Saraswati Nur Hartiningrum, Ni'matus Sa'adatul Ula \\ Sekolah Tinggi Keguruan dan Ilmu Pendidikan PGRI Jombang \\ Jl. Patimura III No.20 Jombang, Jawa Timur, 61418 \\ Email: esty.saraswati88@gmail.com
}

Article History:

Received: 16-06-2019; Received in Revised: 18-08-2019; Accepted: 06-10-2019

\begin{abstract}
Learning will be more meaningful if students are given the opportunity to participate in various learning activities, students can actualize their abilities inside and outside the classroom. Choosing the right learning model can create an atmosphere fun and impact on student activities and learning outcomes. The Index Card Match type cooperative learning model is to find pairs of cards that are quite fun to use to exercises about the material that has been given. The purpose of this study is to determine whether there is influence of cooperative learning model index card match type on student learning outcomes. The research method uses pre-experimental designs with one-group pretest-posttest design models. Technical analysis using hypothesis testing, namely the t-test and correlation, the requirement to do the t-test is to do a normality test. The results of data analysis showed that there was the influence of the Index Card Match type of cooperative learning model on the mathematics learning outcomes of eighth grade students of Sumobito State Junior High School 2. SPSS calculation states that the value of $r$ count $=0.709$, which is located between $0.600<r \leq 0.800$ which means that it is in the high criteria.
\end{abstract}

Keywords: Cooperative Learning; Index Card Match; Learning Outcomes.

\begin{abstract}
Abstrak
Belajar lebih bermakna apabila siswa diberi kesempatan berpartisipasi dalam kegiatan belajar, mengaktualisasikan kemampuan mereka di dalam dan di luar kelas. Memilih model pembelajaran yang tepat dapat menciptakan suasana yang menyenangkan dan berdampak pada kegiatan siswa dan hasil belajar. Model pembelajaran kooperatif tipe Index Card Match menyenangkan digunakan untuk mengulang materi yang telah diberikan. Penelitian ini bertujuan untuk mengetahui pengaruh Index Card Match terhadap hasil belajar siswa. Metode penelitian menggunakan desain pra-eksperimental dengan model desain pretestposttest satu kelompok. Uji hipotesis dilakukan dengan uji-t dan korelasi. Hasil analisis data diperoleh terdapat pengaruh tipe Index Card Match terhadap hasil belajar matematika siswa. Perhitungan SPSS menyatakan bahwa nilai $r$ hitung $=0,709$, yang terletak di antara 0,600 $<r \leq 0.800$ yang berarti berada dalam kriteria tinggi.
\end{abstract}

Kata Kunci: Model Pembelajaran Kooperatif; Index Card Match; Hasil Belajar.

(C)Al-Khwarizmi: Jurnal Pendidikan Matematika dan IImu Pengetahuan Alam. This is an open access article under the CC BY-SA 4.0 license (https://creativecommons.org/licenses/by-sa/4.0/). 


\section{Pendahuluan}

Pendidikan adalah usaha sadar dan terencana untuk mewujudkan suasana belajar dan proses pembelajaran agar siswa aktif mengembangkan potensi dirinya ${ }^{1}$ Pengertian ini merupakan perwujudan perubahan prinsipil undang - undang sistem pendidikan yang berubah dari paradigma pengajaran menjadi paradigma pembelajaran. Pengajaran merupakan istilah yang mewakili peranan dominan guru sebagai pengajar, sedangkan pembelajaran menunjukkan peranan siswa aktif. Pembelajaran merupakan proses aktif siswa yang mengembangkan potensi dirinya ,siswa dilibatkan ke dalam pengalaman yang di fasilitasi oleh guru sehingga siswa mengalir dalam pengalaman melibatkan pikiran, emosi, terjalin dalam kegiatan yang menyenangkan dan menantang sehingga mendorong semangat siswa ${ }^{2}$.

Proses pembelajaran yang didominasi aktivitas guru sedangkan siswa masih banyak menghafal materi yang diberikan, akan menyebabkan siswa bosan dan tidak tertarik dalam proses pembelajaran. Pembelajaran akan lebih bermakna jika siswa diberi kesempatan untuk berpartisipasi dalam berbagai aktivitas kegiatan pembelajaran, sehingga siswa mengaktualisasikan kemampuan di dalam dan di luar kelas ${ }^{3}$. Hasil belajar akan tercapai sesuai tujuan yang diinginkan jika guru dapat membuat siswa aktif dalam pembelajaran dan paham akan materi yang disampaikan oleh guru4. Hasil belajar merupakan kemampuan-kemampuan yang dimiliki siswa setelah ia menerima pengalaman belajarnya ${ }^{5}$. Hasil belajar akan meningkat bila siswa semakin aktif dalam proses belajar mengajar, sehingga hasil belajar yang baik tidak akan didapatkan tanpa adanya aktivitas siswa yang baik ${ }^{6}$

Model pembelajaran kooperatif merupakan model pembelajaran yang membuat siswa menjadi aktif. Model pembelajaran kooperatif adalah model pembelajaran yang terpusat kepada siswa sehingga mampu mengatasi permasalahan guru dalam meningkatkan akitifitas siswa 7. Model

\footnotetext{
1 Presiden Republik Indonesia, “Undang-Undang Republik Indonesia Nomor 20 Tahun 2003 Tentang Sistem Pendidikan Nasional," http://silemkerma.ristekdikti.go.id/assets/panduan/UU_20-2003_Sisdiknas.pdf.

2 Utomo Dananjaya, Media Pembelajaran Aktif(Bandung: Nuansa Cendekia, 2017), 25, http://nuansa.co/katalog/media-pembelajaran-aktif-2/.

3 Rusman, Model-Model Pembelajaran: Mengembangkan Profesionalisme Guru (Jakarta: Rajawali Pers, 2012), 323.

4 Esty Saraswati Nur Nurhartiningrum and Zuli Retno Wati, "Penerapan Teknik Ice Breaking Untuk Meningkatkan Aktivitas Dan Hasil Belajar Siswa Kelas Vii Materi Bilangan Bulat," Journal Proceeding 4, no. 1 (April 20, 2018), https://ejournal.stkipjb.ac.id/index.php/prosiding/article/view/568.

5 Sudjana, Penilaian Hasil Proses Belajar Mengajar (Bandung: Remaja Rosdakarya,
} 2011), 22.

${ }^{6}$ Nurhartiningrum and Wati, "Penerapan Teknik Ice Breaking Untuk Meningkatkan Aktivitas Dan Hasil Belajar Siswa Kelas Vii Materi Bilangan Bulat."

7 Isjoni, Cooperative Learning Mengembangkan Kemampuan Belajar Berkelompok (Bandung: Alfabeta, 2007). 
pembelajaran kooperatif dapat meningkatkan karakter mandiri, hasil belajar matematika siswa ${ }^{8}$, aktivitas siswa ${ }^{9}$, serta pemahaman konsep matematis siswa $^{10}$.

Penelitian ini menggunakan model pembelajaran Index card match. Model pembelajaran ini dapat menciptakan proses pembelajaran yang menyenangkan sehingga dapat menghilangkan rasa bosan pada siswa. Index Card Match adalah mencari pasangan kartu yang cukup menyenangkan digunakan untuk mengulang materi yang telah diberikan ${ }^{11}$. Maksud dari menyenangkan dalam model ini, karena proses dalam pembelajaran siswa berdiri mencari pasangan tidak hanya duduk selama proses pembelajaran berlangsung. Kelebihan dari model kooperatif tipe Index Card Match menumbuhkan kegembiraan dalam proses pembelajaran; mampu menciptakan suasana aktif, memudahkan siswa memahami konsep materi;, timbulnya kerjasama antar pasangan. Pembelajaran dengan menggunakan model kooperatif tipe Index Card Match dapat meningkatkan hasil belajar ${ }^{1213}$

Model pembelajaran kooperatif tipe Index Card Match adalah model pembelajaran yang dapat diaplikasikan diberbagai materi. Materi yang digunakan dalam penelitian ini adalah relasi dan fungsi. Materi ini banyak menggunakan latihan soal agar siswa dapat memahami dan membedakan antara relasi dan fungsi. Index Card Match digunakan untuk mengerjakan latihan soal agar siswa tidak merasa bosan dan jenuh dalam pengerjaan soal, sehingga siswa tidak sadar bahwa dalam mencari pasangan kartu itu siswa masih dalam proses pembelajaran matematika yaitu latihan soal matematika. Penggunaan Index Card Match juga dapat digunakan untuk melihat sejauh mana pemahaman siswa tentang materi yang diajarkan.

${ }^{8}$ Chairil Faif Pasani and Mitra Pramita, "Meningkatkan Karakter Mandiri Dan Hasil Belajar Matematika Siswa Melalui Model Pembelajaran Kooperatif Tipe Think Pair Share (tps) Di Kelas VIII-C Smpn 13 Banjarmasin," Jurnal Pendidikan Matematika 1, no. 2 (August 19, 2014): 17-32, https://doi.org/10.18592/jpm.v1i2.48.

9 Irma Ayuwanti, "Meningkatkan Aktivitas dan Hasil Belajar Matematika Menggunakan Model Pembelajaran Kooperatif Tipe Group Investigation di SMK Tuma'ninah Yasin Metro," SAP (Susunan Artikel Pendidikan) 1, no. 2 (January 16, 2017), https://doi.org/10.30998/sap.v1i2.1017.

${ }^{10}$ Desi Ratnasari, Subandi Subandi, and Fredi Ganda Putra, "Pengaruh Model Pembelajaran Kooperatif Tipe the Power of Two terhadap Pemahaman Konsep Matematis Peserta Didik," Prosiding Seminar Nasional Matematika dan Pendidikan Matematika 2, no. 1 (June 20, 2019): 163-74.

11 Agus Suprijono, Cooperative Learning: Teori Dan Aplikasi PAIKEM (Yogyakarta: Pustaka Pelajar, 2011), 120.

12 Erly Wahyu Akhadiyah Al 'ifah, "Penerapan Model Pembelajaran Kooperatif Tipe Make A Match untuk Meningkatkan Hasil Belajar Materi Segitiga pada Siswa Kelas VII-D SMP Islam Gandusari Trenggalek" 2012, http://repo.iain-tulungagung.ac.id/.

13 Defi Yuniantika and Esti Harini, "Penerapan Metode Pembelajaran Index Card Match Untuk Meningkatkan Minat Dan Prestasi Belajar Matematika Siswa Kelas III SD N Wirokerten," TRIHAYU: Jurnal Pendidikan Ke-SD-An 4, no. 2 (February 8, 2018), https://doi.org/10.30738/trihayu.v4i2.2241. 
Berdasarkan latar belakang masalah diatas, maka rumusan masalah dalam penelitian ini adalah Adakah Pengaruh Model Pembelajaran Kooperatif Tipe Index Card Match Terhadap Hasil Belajar Siswa Pada Mata Pelajaran Matematika Materi Relasi dan Fungsi Kelas VIII SMP Negeri 2 Sumobito?. Tujuan dari penelitian ini adalah untuk mengetahui ada tidaknya pengaruh model pembelajaran kooperatif tipe index card match terhadap hasil belajar siswa pada mata pelajaran matematika materi relasi dan fungsi kelas viii smp negeri 2 sumobito.

\section{Metode}

Penelitian ini bersifat kuantitatif dengan desain pre-experimental designs model one-group pretest-posttest design. Populasi yang digunakan adalah siswa kelas VIII SMP Negeri 2 Sumobito tahun ajaran 2018/2019 yang berjumlah tujuh kelas. Masing-masing kelas berjumlah 30 orang. Sampel yang digunakan adalah kelas VIII-G yang diambil dengan teknik cluster random sampling. Kelas tersebut selanjutnya diterapkan model pembelajaran kooperatif tipe Index Card Match. Penelitian ini dilakukan pada semester genap tahun ajaran 2018/2019. Instrumen yang digunakan adalah tes hasil belajar yang berisi 5 soal uraian dengan waktu 40 menit. Tes yang digunakan terbagi menjadi pretest (sebelum diberikan perlakuan) dan posttest (setelah diberikan perlakuan). Soal pretest dan posttest dibuat berbeda namun dalam satu kompetensi dasar yang sama. Sebelum digunakan, soal tes tersebut diuji validitas dan reliabilitasnya.

Analisis data menggunakan SPSS versi 20. Hipotetsis diuji dengan taraf signifikan 5\%. Hipotesis yang ingin duji adalah ada pengaruh model pembelajaran kooperatif tipe Index Card Match terhadap hasil belajar matematika siswa.

\section{Hasil dan Diskusi}

RPP dalam kegiatan pembelajaran disusun berdasarkan kurikulum 2013, dengan model pembelajaran kooperatif tipe index card match. Dari hasil validasi ahli diperoleh bahwa RPP sudah valid dan dapat digunakan. Hasil validasi RPP dapat dilihat pada Tabel 1. 
Tabel 1. Hasil Validasi RPP

\begin{tabular}{ccc}
\hline No & RPP Sebelum Validasi & RPP Sesudah Validasi \\
\hline & & Sumber belajar ditulis seperti \\
& daftar pustaka menjadi \\
& Penulisan sumber belajar & Kementrian Pendidikan dan \\
kurang tepat: Buku paket & Kebudayaan. 2017. \\
& matematika SMP/MTs kelas VIII & MATEMATIKA SMP/MTs Kelas \\
& & VIII Semester 1. Jakarta : Pusat \\
& Kurikulum, dan perbukuan, \\
& RPP sebelum validasi tidak & kemendikbud. \\
diberikan tulisan fase-fase & RPP sesudah validasi diberikan \\
dalam kegiatan pembelajaran & tulisan fase-fase dalam kegiatan \\
yang menunjukkan langkah & pembelajaran yang menunjukkan \\
model pembelajaran yang & langkah model pembelajaran \\
digunakan. & yang digunakan \\
& &
\end{tabular}

Validitas tes hasil belajar (pretest dan posttest) dihitung menggunakan validitas empirik dengan bantuan SPSS versi 20. Hasil validitas yang diperoleh cukup tingi dan tinggi. Hasil uji reliability juga berada pada kategori tinggi sengan nilai Cronbach's Alpha 0,6. Dengan demikian tes hasil belajar dapat digunakan sebagai instrument dalam penelitian ini.

Hasil uji normalitas data menggunakan Kolomogorov-Smirnov test seperti Tabel 2 .

Tabel 2. Uji Normalitas Data menggunakan Kolomogorov Smirnov Test

\begin{tabular}{|c|c|c|c|}
\hline & & Pretest & Posttest \\
\hline \multicolumn{2}{|c|}{$\mathrm{N}$} & 30 & 30 \\
\hline \multirow{2}{*}{ Normal Parameters ${ }^{a, b}$} & Mean & 72.67 & 87.53 \\
\hline & Std. Deviation & 16.597 & 5.104 \\
\hline \multirow{3}{*}{$\begin{array}{l}\text { Most Extreme } \\
\text { Differences }\end{array}$} & Absolute & .171 & .157 \\
\hline & Positive & .127 & .157 \\
\hline & Negative & -.171 & -.095 \\
\hline \multicolumn{2}{|c|}{ Kolmogorov-Smirnov Z } & .935 & .859 \\
\hline \multicolumn{2}{|c|}{ Asymp. Sig. (2-tailed) } & .346 & .452 \\
\hline
\end{tabular}

a. Test distribution is Normal.

b. Calculated from data.

Berdasarkan Tabel 2 terlihat skor Asymp. Sig. (2-tailed) untuk pretest dan posttest keduanya $\geq 0,05$. Artinya data hasil belajar pretest dan posttest keduanya terdistribusi normal. Sehingga analisis inferensial dapat dilanjutkan.

Data hasil belajar preetest dan posttest berdistribusi normal, sehingga analisis data dilanjutkan pada uji-t untuk mengetahui ada tidaknya 
perbedaaan rata-rata hasil belajar siswa dengan menggunakan paired sample t-test.

Tabel 3. Uji Perbedaan Dua rata-Rata

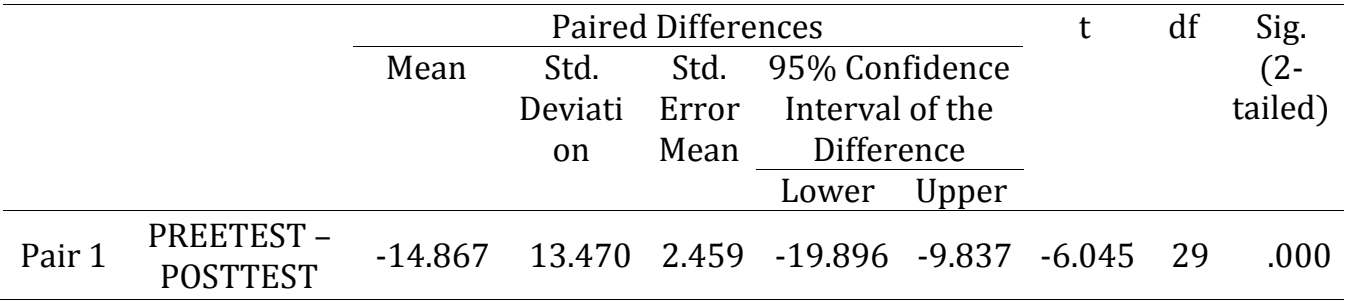

Berdasarkan Tabel 3, terlihat nilai sig.(2-tailed) sebesar 0,000. Sig. (2tailed) $<\alpha$ dimana $\alpha=0,05$. Artinya ada perbedaan hasil belajar matematika siswa kelas VIII SMP Negeri 2 Sumobito sebelum dan sesudah diberi perlakuan dengan menggunakan model pembelajaran kooperatif tipe Index Carsd Match. Untuk mengetahui ada pengaruh tidaknya terhadap hasil belajar maka di lanjutkan dengan uji korelasi.

Tabel 4. Korelasi Skor Tes Hasil Belajar

\begin{tabular}{ccrr}
\hline & & PREETEST & POSTTEST \\
\hline \multirow{3}{*}{ PREETEST } & Pearson Correlation & 1 & $.709^{* *}$ \\
\cline { 2 - 4 } & Sig. (2-tailed) & 30 & .000 \\
\cline { 2 - 4 } & $\mathrm{N}$ & $.709^{* *}$ & 30 \\
\hline \multirow{3}{*}{ POSTTEST } & Pearson Correlation & .000 & 1 \\
\cline { 2 - 4 } & Sig. (2-tailed) & 30 & 30 \\
\cline { 2 - 4 } & $\mathrm{N}$ & &
\end{tabular}

Berdasarkan Tabel 4, nilai sig.(2-tailed) sebesar 0,000 $<0,05$. Artinya ada pengaruh model pembelajaran kooperatif tipe Index Card Match terhadap hasil belajar matematika siswa.

Penerapan model pembelajaran kooperatif tipe Index Carsd Match pada siswa kelas VIII SMP Negeri 2 Sumobito berpengaruh pada hasil belajar matematika siswa. Siswa dapat mengerjakan soal dengan senang dan antusias sehingga siswa senang mengikuti proses pembelajaran. Siswa tidak menyadari ketika proses mencari pasangan kartu siswa juga berpikir untuk mendapatkan jawaban dari soal yang diberikan sehingga mendapatkan pasangan sesuai dengan kartu soal yang diberikan. Siswa antusias untuk mencari pasangan lebih dulu. Pembelajaran dikelas tidak monoton. Siswa dilibatkan aktif dalam proses pembelajaran. Hal ini sejalan dengan pendapat Suprijono bahwa keunggulan dalam model pembelajaran kooperatif tipe Index Card Match menumbuhkan kegembiraan dalam proses pembelajaran, 
mampu menciptakan suasana aktif, memudahkan siswa memahami konsep materi ${ }^{14}$.

Secara deskriptif, data hasil belajar antara pretest dan post test memiliki perbedaaan. Hasil belajar siswa setelah diterapkan model pembelajaran kooperatif tipe index card match lebih baik daripada sebelum diberikan perlakuan. Sebelum siswa diberikan model pembelajaran kooperatif tipe index card match pada materi relasi dan fungsi. Nilai rata-rata pada tes hasil belajar tersebut adalah 72,7 dengan nilai minimum 42 dan nilai maksimum 94, setelah dilakukan proses pembelajaran menggunakan model pembelajaran kooperatif tipe index cad match kemudian dilakukan tes. Nilai rata-rata pada tes hasil belajar tersebut adalah 87,5 dengan nilai minimum 77 dan nilai maksimum 97. Hasil ini sejalan dengan hasil penelitian Fitri Wulandari dan Rosida Rakhmawati yang menyatakan bahwa kemampuan pemahaman relasional matematis siswa yang diajar dengan Index Card Match lebih baik dibandingkan dengan metode pmebelajaran konvensional15.

Hasil analisis korelasi menunjukkan model pembelajaran kooperatif tipe Index Card Match berpengaruh terhadap hasil belajar matematika siswa. Hasil Penelitian ini sejalan dengan penelitian yang dilakukan oleh Wahyu' ${ }^{16}$, Yuniantika ${ }^{17}$, dan Gorgonia yang menyatakan model kooperatif tipe Index Card Match berpengaruh terhadap hasil belajar matematika, hal ini dilihat dari perbedaan tes hasil belajar yang diberikan sebelum dan sesudah diberikan perlakuan.

\section{Kesimpulan}

Artikel ini telah menunjukkan bahwa model pembelajaran Kooperatif Tipe Index Card Match berpengaruh terhadap hasil belajar matematika siswa pada materi relasi dan fungsi kelas VIII SMP Negeri 2 Sumobito. Model pembelajaran kooperatif tipe index card match dapat dijadikan salah satu alternatif model pembelajaran sehingga siswa semangat dan tidak merasa bosan dalam pengerjaan latihan soal. Pada penerapan tipe index card match, jumlah soal latihan harus disesuaikan dengan jumlah siswa dan waktu yang ada. Pada tahap mencari pasangan kartu, guru harus dapat mengkondisikan kelas agar tidak menimbulkan suasana ramai yang dapat mengganggu kelas lain.

${ }^{14}$ Agus Suprijono, Cooperative Learning: Teori Dan Aplikasi PAIKEM.

${ }^{15}$ Fitri Wulandari and Rosida Rakhmawati, “Analisis Kemampuan Pemahaman Relasional Matematis : Dampak Strategi Pembelajaran Index Card Match,” Desimal: Jurnal Matematika 2, no. 3 (September 30, 2019): 203-9, https://doi.org/10.24042/djm.v2i3.4291.

${ }^{16}$ Erly Wahyu Akhadiyah Al 'ifah, "Penerapan Model Pembelajaran Kooperatif Tipe Make A Match untuk Meningkatkan Hasil Belajar Materi Segitiga pada Siswa Kelas VII-D SMP Islam Gandusari Trenggalek.”

17 Yuniantika and Harini, "Penerapan Metode Pembelajaran Index Card Match Untuk Meningkatkan Minat Dan Prestasi Belajar Matematika Siswa Kelas III SD N Wirokerten." 


\section{Daftar Pustaka}

Agus Suprijono. Cooperative Learning: Teori Dan Aplikasi PAIKEM. Yogyakarta: Pustaka Pelajar, 2011.

Ayuwanti, Irma. "Meningkatkan Aktivitas dan Hasil Belajar Matematika Menggunakan Model Pembelajaran Kooperatif Tipe Group Investigation di SMK Tuma'ninah Yasin Metro." SAP (Susunan Artikel Pendidikan) 1, no. 2 (January 16, 2017). https://doi.org/10.30998/sap.v1i2.1017.

Erly Wahyu Akhadiyah Al 'ifah. "Penerapan Model Pembelajaran Kooperatif Tipe Make A Match untuk Meningkatkan Hasil Belajar Materi Segitiga pada Siswa Kelas VII-D SMP Islam Gandusari Trenggalek," 2012. http://repo.iain-tulungagung.ac.id/.

Isjoni. Cooperative Learning Mengembangkan Kemampuan Belajar Berkelompok. Bandung: Alfabeta, 2007.

Nurhartiningrum, Esty Saraswati Nur, and Zuli Retno Wati. "Penerapan Teknik Ice Breaking Untuk Meningkatkan Aktivitas Dan Hasil Belajar Siswa Kelas Vii Materi Bilangan Bulat." Journal Proceeding 4, no. 1 (April 20,

2018). https://ejournal.stkipjb.ac.id/index.php/prosiding/article/view/568.

Pasani, Chairil Faif, and Mitra Pramita. "Meningkatkan Karakter Mandiri Dan Hasil Belajar Matematika Siswa Melalui Model Pembelajaran Kooperatif Tipe Think Pair Share (tps) Di Kelas VIII-C Smpn 13 Banjarmasin." Jurnal Pendidikan Matematika 1, no. 2 (August 19, 2014): 17-32. https://doi.org/10.18592/jpm.v1i2.48.

Presiden Republik Indonesia. "Undang-Undang Republik Indonesia Nomor 20 Tahun 2003 Tentang Sistem Pendidikan Nasional," n.d. http://silemkerma.ristekdikti.go.id/assets/panduan/UU_202003_Sisdiknas.pdf.

Ratnasari, Desi, Subandi Subandi, and Fredi Ganda Putra. "Pengaruh Model Pembelajaran Kooperatif Tipe the Power of Two terhadap Pemahaman Konsep Matematis Peserta Didik." Prosiding Seminar Nasional Matematika dan Pendidikan Matematika 2, no. 1 (June 20, 2019): 16374.

Rusman. Model-Model Pembelajaran: Mengembangkan Profesionalisme Guru. Jakarta: Rajawali Pers, 2012.

Sudjana. Penilaian Hasil Proses Belajar Mengajar. Bandung: Remaja Rosdakarya, 2011.

Utomo Dananjaya. Media Pembelajaran Aktif. Bandung: Nuansa Cendekia, 2017. http://nuansa.co/katalog/media-pembelajaran-aktif-2/.

Wulandari, Fitri, and Rosida Rakhmawati. "Analisis Kemampuan Pemahaman Relasional Matematis: Dampak Strategi Pembelajaran Index Card Match." Desimal: Jurnal Matematika 2, no. 3 (September 30, 2019): 203-9. https://doi.org/10.24042/djm.v2i3.4291.

Yuniantika, Defi, and Esti Harini. "Penerapan Metode Pembelajaran Index Card Match Untuk Meningkatkan Minat Dan Prestasi Belajar Matematika Siswa Kelas III SD N Wirokerten." TRIHAYU: Jurnal Pendidikan Ke-SD-An 4, no. 2 (February 8, 2018). https://doi.org/10.30738/trihayu.v4i2.2241. 